\title{
Trends and hot topics in green open space and ecological wisdom research
}

\author{
Rosyi Damayanti T. Manningtyas ${ }^{\mathrm{a}, \mathrm{b}, *}$, Katsunori Furuya ${ }^{\mathrm{b}}$ \\ ${ }^{a}$ Department of Landscape Architecture, IPB University, Bogor 16680, Indonesia \\ ${ }^{b}$ Department of Environmental Science and Landscape Architecture, Chiba University, Chiba 271-8510, Japan
}

\section{Article history:}

Received: 2 October 2020 / Received in revised form: 28 November 2020 / Accepted: 2 December 2020

\begin{abstract}
Studies on green open space and ecological wisdom have developed over time and are linked to various subjects and impacts. However, both research subjects have developed somewhat independently despite their approaches often achieving a sustainable landscape. This research proposed the bibliometric analysis of green open space and ecological wisdom research to identify the trends and hot topics on both aspects, and determine a potential topic for future research related to both subject areas. We collected journals from the last decades from Scopus database using appropriate keywords and analysed the metadata using VOSviewer program. The text data were then extracted from the title and abstract of the document collections using VOSviewer built-in text mining function. The hot topic term was analysed by calculating the average score of citation based on their occurrences. Finally, potential research in green open space and ecological wisdom field was determined by overlaying the findings and catching the slice. Of a total of 283 document collections analysed, 75 most relevant terms were found. All terms were divided into four clusters as a research field: urban green space cluster, environmental quality cluster, sustainable planning cluster, and landscape development cluster. Further, the hot topic analysis found ten keywords that had a high citation impact on document collection and mostly came from a sustainable planning cluster. After overlaying the findings, six terms emerged that have a high potential for future research for their high citation impact on science.
\end{abstract}

Keywords: ecological wisdom; green open space; landscape; text mining; VOSviewer

\section{Introduction}

Recently, the need for green open spaces has increased along with an increase in knowledge about its benefits and roles for life quality, especially in urban areas where green open space is essential for increasing biodiversity, such as through the remnant habitats. Some benefits of green open space in urban areas include air and water purification, mitigation of the effects of environmental pollution, carbon sequestration, microclimate regulation, urban, recreational, spiritual and habitat for therapeutic wildlife value and social integration. Green space improves the quality of the environment, urban tourism, active and passive recreation and other urban ecological functions [1,2]. The ecological benefits bestowed in green areas range from protecting and maintaining biodiversity to help in the mitigation of change. As urban green open spaces contribute to human and social wellbeing, they are essential for livable and sustainable cities [3].

On the other hand, there is an ecological wisdom concept that has emerged since 1980s, and was declared as a new concept of landscape development in 2014. It is defined as good property design that require minimal intervention ecologically and socially [4]. This idea originated from the concept of returning to the local culture, which has been proven over the years to integrate human behaviors and nature to produce a sustainable landscape. The ecological wisdom

* Corresponding author. Tel.: +81 8073273765 .

Email: rosyi.damayanti88@gmail.com / rosyi.damayanti@chiba-u.jp. concept emphasizes on ideas, principles, and strategies that have historically been proven, specifically to the location and context, and leads to the creation of long-term sustainability.

Both green open space and ecological wisdom play an important role on sustainable landscape development [5-9]. They improve the life quality by fulfilling the human basic needs on space in the landscape according to human value and their way of life. Firmansyah (2016) stated that smart city development should be supported by local wisdom to maintain the sustainability of landscape [10].

The study on green open space and ecological wisdom has developed over time and links to various subjects and impacts. Scopus identified at least 290 papers since 1971, which discussed about the green open space topic and 101 papers since 1984, which discussed about the topic of ecological wisdom. However, both research subjects developed somewhat independently despite their approaches often used in urban and environmental development as an effort to achieve a sustainable landscape and thereby sustainable development goal (SDGs) [11], [6]. Research development on green open space topic has expanded to various topic including its role for ecology [12] [13,14]. Moreover, in locality context, some research on ecological wisdom are related to green space such as traditional garden [15], biodiversity [16-18], and protected forest [19]. Finally, it is challenging to identify a relationship between both topics and obtain a direction for future research, which would be useful for sustainable landscape development.

The bibliometric analysis of green open space and ecological wisdom research discussed in this research was to 
identify the trends and hot topics on both subjects. Furthermore, the findings from this research could determine the potential research for future. Bibliometric analysis evaluates the progress and development of knowledge on the topic of research [20]. It is applied to the literature and metadata publications to understand the paradigm and dynamics of the development of science [21].

The concept of science contained in a document is seen through the use of co-word. Co-word analysis is based on the co-occurrence analysis of words or keywords from two or more documents used to index documents as mentioned by Diodato 1994 in [20]. It is intended to analyze content, patterns, and trends of a document by measuring the strength of a term. Co-word analysis is used to calculate the number of keywords of research documents that appear simultaneously in the article under study. These keywords are determined by the author. Thus, the relationship between the documents becomes stronger when more of the same keywords occur in document collection [22]. Furthermore, the distribution of this co-word is determined by its co-occurrences in a co-word map. The essential and unique terms featured in the title and abstract are analyzed to represent a concept.

VOSviewer is a free computer program for visualizing and exploring maps of bibliometric knowledge. The algorithm used in this program is almost similar with multi-dimensional scaling (MDS). VOSviewer produces a cluster that is automatically displayed in color on the map. The clustering algorithm operates with a parameter $(\mathrm{y})$ that can be changed to obtain more or fewer clusters, and displays the co-word map analysis based on the co-occurrence of the term in papers. The advantage of VOSviewer is that it uses the text mining function to identify the combination of noun phrases relevant to mapping and integrated clustering approaches to examine co-citation network data and co-occurrence. Although many programs analyze text units and matrix similarities, the visualizations provided by VOSviewer are an advantage [23] and interactive program options and functions make it easy to access and explore.

\section{Materials and Methods}

\subsection{Data Collecting}

The data were collected from the Scopus database using "green open space" or "ecological wisdom" as keywords in article title, abstract, and keyword on December 18, 2019. The string (“...") was used to narrow the findings. We collected English research article documents, which were published in the last decade from 2009 to 2019.

Currently, the Scopus platform is the largest academic article database and covers science and social science fields. Falagas et al. (2008) stated that Scopus has higher consistency and conformity than other leading indexers, such as the Web of Science and Google Scholar [24].

In the data collection stage, 283 documents related to the topics of green open space and ecological wisdom were found. The documents metadata used in the analysis stage included author(s), title, abstract, citation, publication year, references, and sources. The publication information was downloaded as a CSV file for further processing by the
VOSviewer application. The Scopus analysis of document result also was downloaded to describe the publication data in brief, and descriptive analysis was conducted to analyze the trend between them.

\subsection{Data Analysis}

Text data were extracted from the title and abstract of the document for analysis using the VOSviewer built-in text mining function (25) and counting the words by the full counting methods. VOSviewer offers two counting techniques: full counting and binary counting. The full counting method is all occurrences of a term in a document (in this case, title and abstract for each article) used to assess cooccurrence relationships among terms. Binary counting refers to term calculation only using the presence or absence of a term in a document (26). Nevertheless, van Eck and Waltman (2014) stated that neither method is not significantly different, especially for a small data set [25].

Based on the full counting method, 7739 terms were found and filtered into 87 terms occurred a minimum of 20 times to qualify. Furthermore, 75 most relevant terms were chosen to displayed and analyzed by excluding the unrelated or familiar words and merged repetitive words by applying the thesaurus files. The hot topic terms were also analyzed by calculating their average score of citation based on their occurrences. It was conducted by normalizing the citation score, which was divided by mean and color range from 0.5 to 2.5 and more.

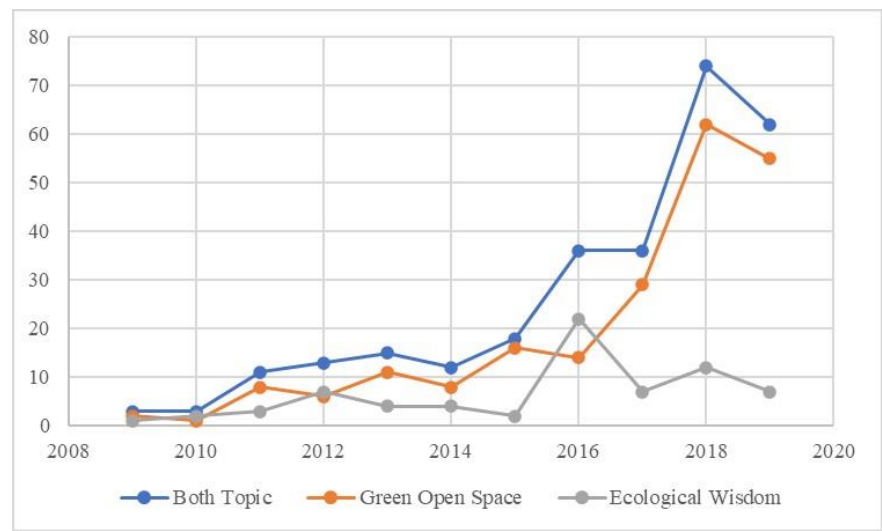

Fig. 1. The number of documents by year according to Scopus data

\section{Results and Discussion}

\subsection{Publication Overview}

The number of publications is an important factor to show the development trends in scientific research. Regarding the methodology previously described, 283 research articles related to green open space and ecological wisdom research from 2009 to 2019 were found. 215 documents were related to the green open space field, while 68 documents were related to the ecological wisdom field. Figure 1 shows the number of documents per topic per year. In general, the research interest in both fields is increasing annually. After stagnancy in 2009, the increase in number of publications has fluctuated and reached a peak in 2018. Upon zooming out, it is seen that the 
green open space topic was discussed more extensively as compared to the ecological wisdom field. The 'orange line' in figure represents the green open space topic, which increased significantly in 2017, whereas the 'grey line' which represents the ecological wisdom topic and is relatively stable, fluctuated from 2015 to 2017, and reached a peak in 2016.

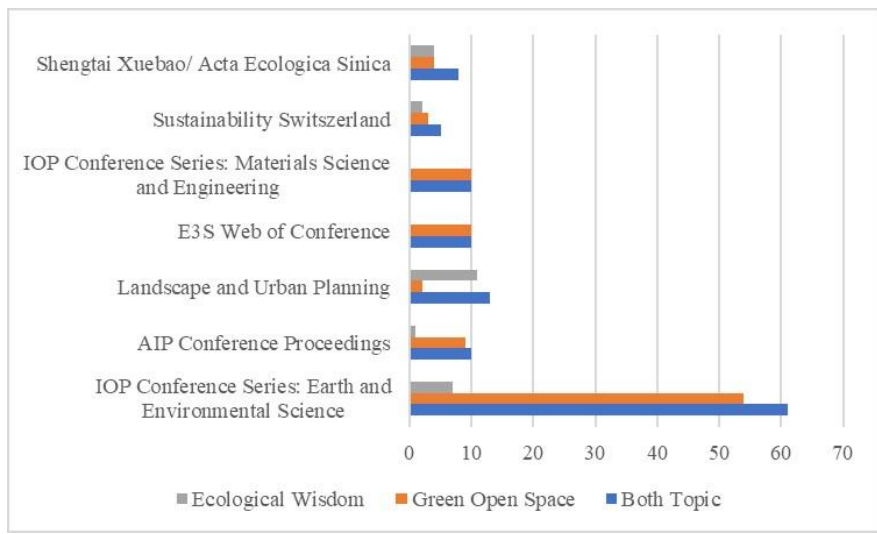

Fig. 2. The number of documents by source according to Scopus data

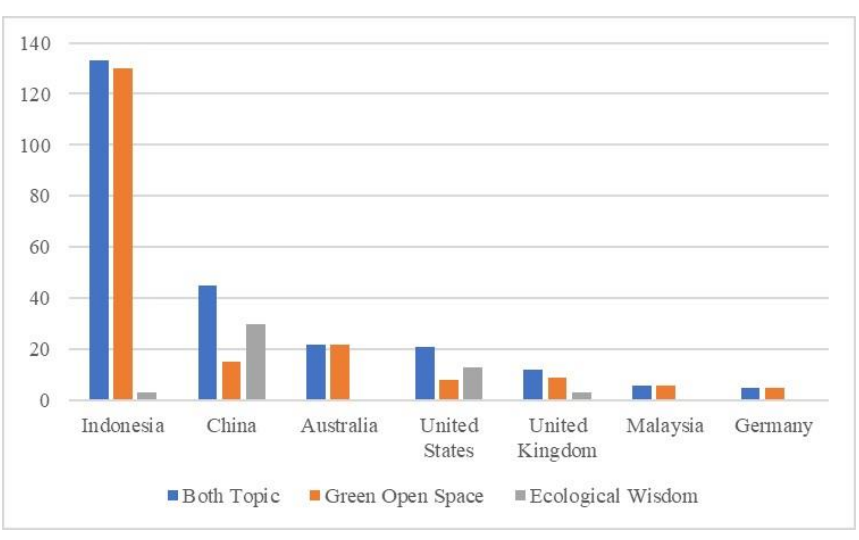

Fig.3. The number of documents by country according to Scopus data

The publication source of document collection was also identified and 104 sources that published both topics were found. In all, $22 \%$ of documents were published in "IOP Conference Series Earth and Environmental Sciences" from 2017 to 2019 followed by "Landscape and Urban Planning" (4.5\%), "AIP Conference Proceeding" (3.5\%), and "IOP Conference Series Materials Science and Engineering" (3.5\%). Most articles were published in 100 other journals less frequently. Upon zooming out of the data analysis in Figure 2, it was found that most of the green open space research were published in international conference proceedings, while ecological wisdom research were published in international journals.

Interestingly, when arranged by country, most document collections came from Indonesia and China, followed equally by Australia and the USA (Figure 3). Therefore, it could be assumed that these four countries were most interested in these topics. Further, Figure 3 shows the trend of both topics by country. It reveals that the green open space topic is mostly discussed in Indonesia and Australia, whereas ecological wisdom is mostly discussed in China and the USA.

\subsection{Research Trends for Last Decades}

To analyze the research trends from 2009 to 2019, we extracted 7739 terms from tittles and abstracts of 283 documents collected using VOSviewer's text mining function. From this stage, we found 87 terms occurred at least 20 times and filtered them through the thesaurus file into the 75 most relevant terms. Figure 4 shows the results of the term cooccurrence map to show the trends in green open space and ecological wisdom research.

There are four clusters identified by VOSviewer and are illustrated in different colors: red, green, blue, and yellow. We labelled each cluster manually based on the observed keywords that most expressed linked all terms in the cluster. For example, in the red cluster, green open space and urban area are terms with high occurrences and can express all terms in the cluster; consequently, we named this cluster as the urban green space cluster. Similarly, the green, blue, and yellow clusters were labelled as environmental quality, sustainable planning, and landscape development respectively.

Figure 4 shows the term map of the document collection. There are 75 terms divided into 4 clusters. The red clusters contained 27 terms related to urban green space fields, such as green open space, settlement, flooding, policy, water, urban forest, and urban area. The green clusters contained 17 terms related to the environmental quality topic such as environment, quality, resident, child, park, and activity. Similarly, the blue cluster contained 16 terms related to sustainable planning such as ecological wisdom, sustainable, planning, nature, influence, and construction. Finally, the yellow cluster is a landscape development cluster that discusses 13 terms such as landscape, development, approach, concept, function, and role.

Table 1. The Most Relevant Term n Green Open Space and Ecological Wisdom Research

\begin{tabular}{|c|c|c|}
\hline Cluster & Terms & TLS \\
\hline $\begin{array}{l}\text { Urban green space (red } \\
\text { points) }\end{array}$ & $\begin{array}{l}\text { Green open space, Area, Value, Urban Area ,Indonesia, Data, Need, Change, } \\
\text { Population, Land, Jakarta, Year, Water, Settlement, Distribution, Number, Policy, } \\
\text { Type, Tree, Effort, Land use, Government, Species, Implementation, Increase, } \\
\text { Amount, Addition, Flooding, Urban Forest }\end{array}$ & 49734 \\
\hline $\begin{array}{l}\text { Environmental quality } \\
\text { (green points) }\end{array}$ & $\begin{array}{l}\text { Environment, Quality, Space, Activity, Community, Park, Factor, Open Space, } \\
\text { Facility, Life, Health, Use, time, Benefit, Environmental Quality, Resident, Child }\end{array}$ & 27702 \\
\hline $\begin{array}{l}\text { Sustainable planning } \\
\text { (blue points) }\end{array}$ & $\begin{array}{l}\text { Planning, Paper, Sustainability, Ecological wisdom, Effect, Person, Nature, Building, } \\
\text { Construction, Aspect, Relationship, Form, China, Influence, Importance, Article }\end{array}$ & 19046 \\
\hline $\begin{array}{l}\text { Landscape } \\
\text { development (yellow } \\
\text { points) }\end{array}$ & $\begin{array}{l}\text { Development, Landscape, Process, Region, Approach, Concept, Function, Role, } \\
\text { Order, Information, Place, Way, Application }\end{array}$ & 24746 \\
\hline
\end{tabular}


The total link strength (TLS) indicates the total strength of the link of a term with another term [25]. It is used to predict the trend of research. Table 1 shows that the red cluster contained the highest number of terms and had the highest total link strength value, followed by the green, yellow, and blue clusters. This indicated that the research trend in the last decade focused urban green space topics and was supported by environmental quality, landscape development, and sustainable planning topics.

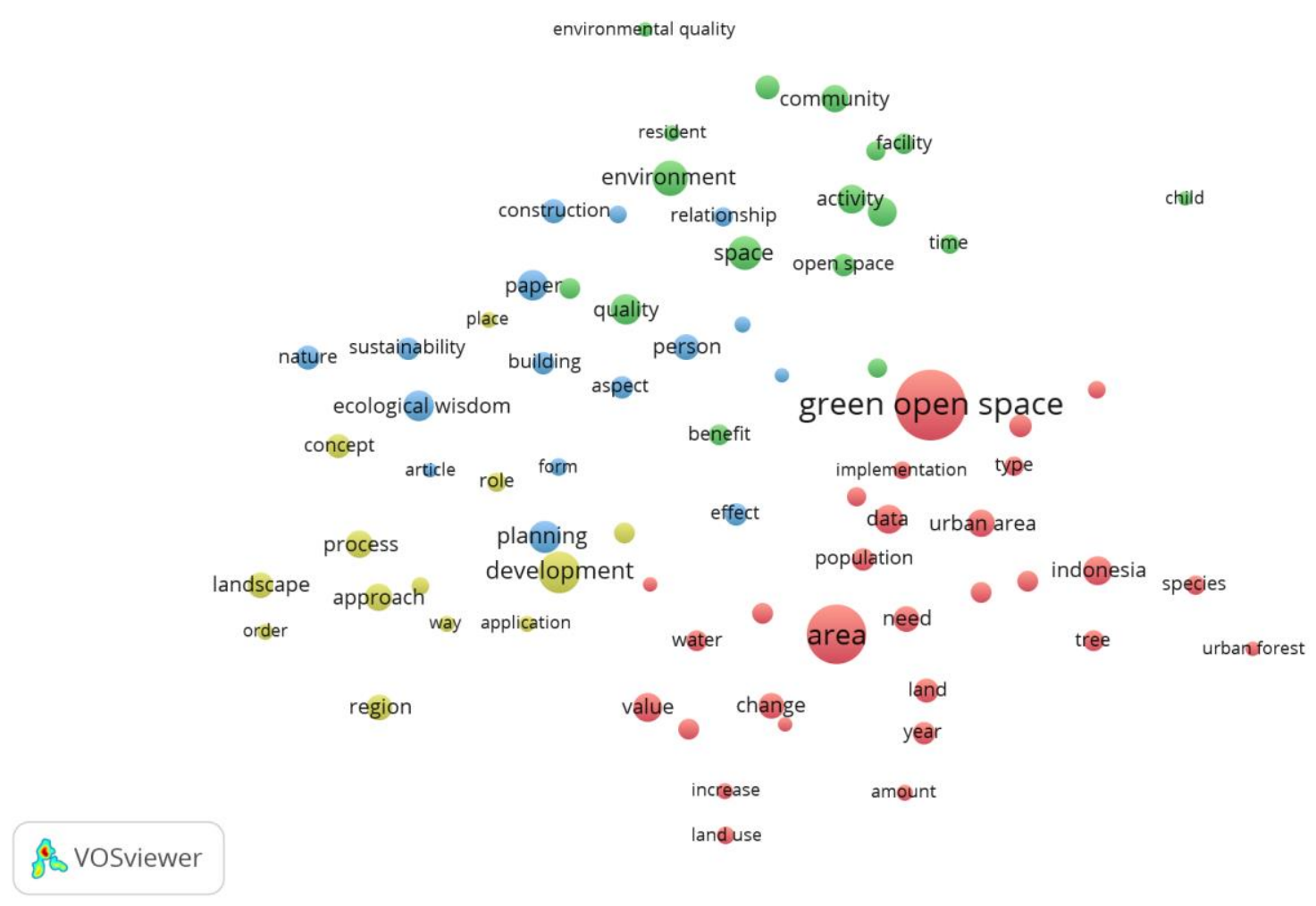

Fig. 4. Co-occurrence map of document collection

Moreover, the relevancies of term indicated the larger differences of two distribution over noun phrase. The noun phrase with high relevance has significantly bias distribution towards other noun phrase and tend to represent specific topics covered by the text data. Whereas, the low relevance noun phrase had less equal distribution towards another noun phrase and tended to represent general topic, which was not to be representative of any specific topic [25]. Table 2 shows 10 terms with the highest relevance representing the most specific topic discussed in document collection. The specific terms tended to have little occurrences. It indicated that these terms are still limited to be discussed and potential to be a research topic in the future.

On the other hand, the location between cluster also described the closeness of the study [25]. Figure 4 shows that green, blue, and yellow clusters were located close to each other and diffused, so there were no clear boundaries. It represented the convergence between environmental quality, landscape development, and sustainable planning topics, meaning that research collaboration among researchers of

Table 2. The Highest Relevance Noun Phrase in Green Open Space and Ecological Wisdom Research

\begin{tabular}{lccc}
\hline \multicolumn{1}{c}{ Terms } & Occurrences & Relevance & Cluster \\
\hline Tree & 49 & 2.75 & Urban Green space \\
Species & 47 & 4.55 & Urban Green Space \\
Urban forest & 25 & 7.86 & Urban Green Space \\
Child & 28 & 2.71 & Environmental Quality \\
Ecological wisdom & 110 & 2.07 & Sustainable Planning \\
Nature & 68 & 2.53 & Sustainable Planning \\
Landscape & 78 & 3.73 & Landscape Development \\
Process & 85 & 2.43 & Landscape Development \\
Region & 76 & 2.12 & Landscape Development \\
Order & 31 & 3.72 & Landscape Development \\
\hline
\end{tabular}


these topics was conducted. Convergence itself is defined as a condition in which boundaries between filed of science are blurred and processed to combine with another field. Generally, some innovative solutions come out of convergence [27].

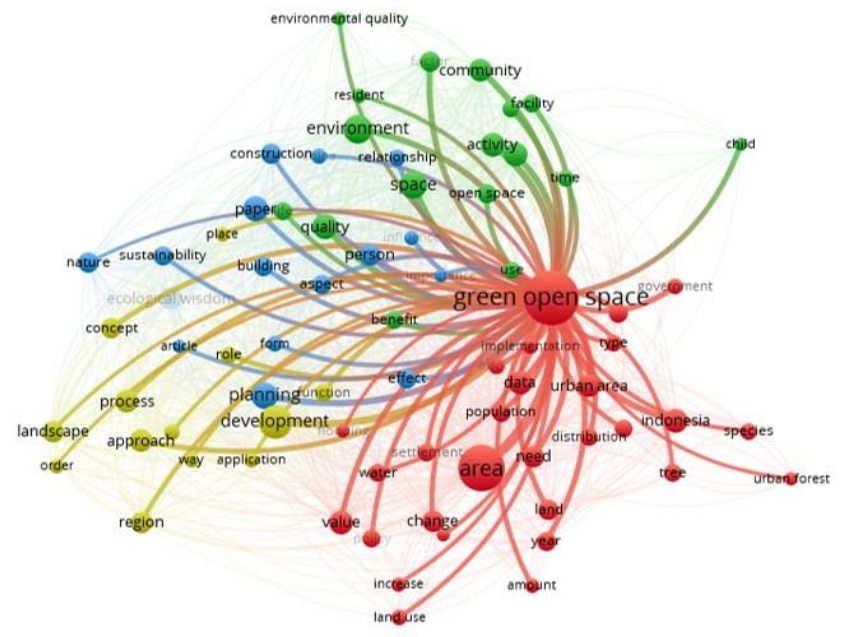

(a)

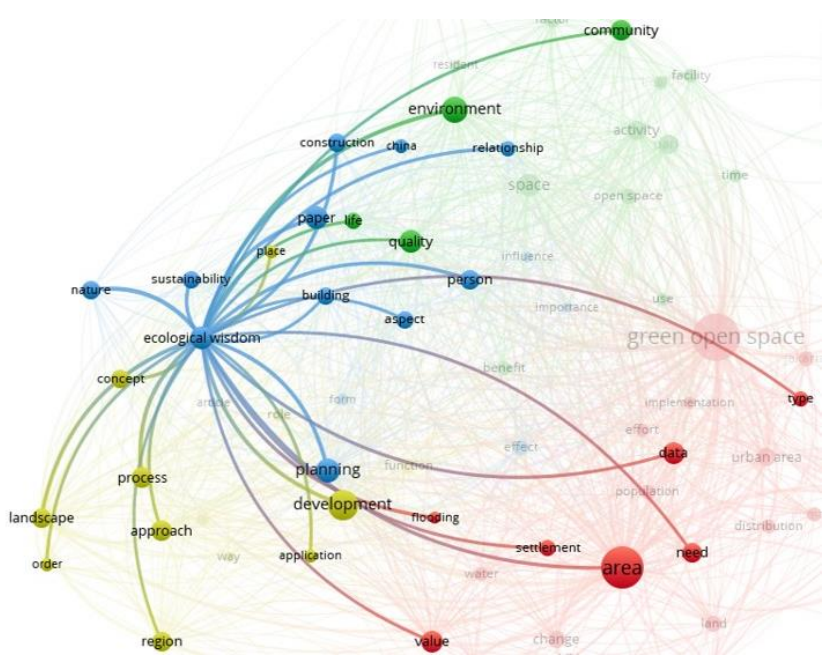

(b)

Figure 5. Green Open Space and Ecological Wisdom Network

\subsection{The Relation Between Green Open Space and Ecological Wisdom Topic}

Van Eck and Waltman (2018) stated that terms with a high relevance score tend to represent specific topics covered by the text data, while terms with a low relevance score tend to be general and not as the representative of any specific topic [25]. The green open space term had the highest occurrences value (562 occurrences), but low relevance ( 0.52 relevance). It meant that the green open space term has been widely discussed and correlated with a variety of topics. This was proven by the link number of the green open space terms. The green open space term became the core of the topic discussion and connected to 73 other terms, except the ecological wisdom term (Figure 5a). This indicated that the green open space term and ecological wisdom term never appeared together in document collection or that neither topic had a correlation in research. In other words, there has never been research discussing both topics together in the last ten years.

Next, the ecological wisdom term occurred 110 times in the document collection with a relevance score of 2.07. According to van Eck and Waltman (2018), this term is explicitly used by the researcher and is still limited to discussion [25]. It is described in Figure 5b, where the ecological wisdom term is linked to only 30 other terms, especially in the sustainable planning cluster. Based on its location, the ecological wisdom term is close to sustainability, nature, and place terms. This indicates that research on ecological wisdom is often correlated with sustainability concept, nature, and is specific to a location.

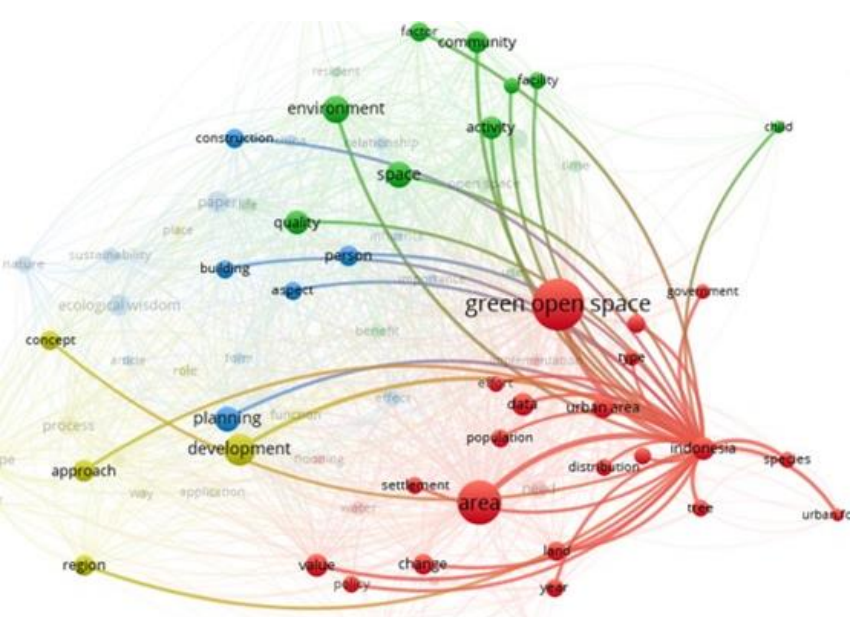

(a)

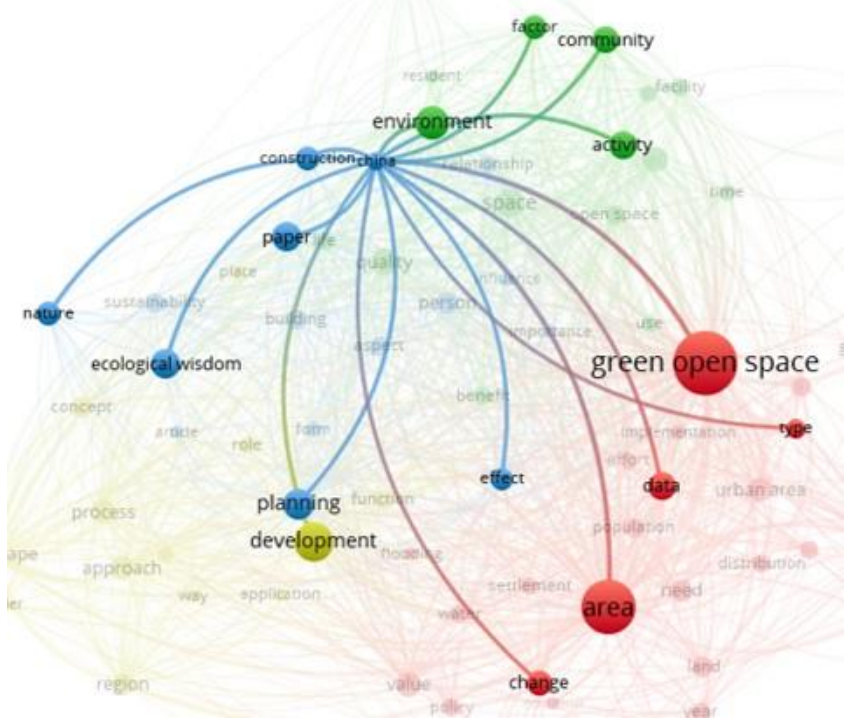

(b)

Figure 6. Indonesia (a) and China (b) research trends according to both topic

\subsection{Indonesia and China's Trends In Research}

Indonesia and China are two countries that appeared more than 20 times in the document collection. Indonesia as a term occurred 94 times and linked to 39 terms, while China occurred 37 times and linked to 16 terms (Figure 6). Noticeably, the link strength value of both terms related to the 
green open space term and ecological wisdom term are interesting.

The link strength of Indonesia and the green open space term were 271 times. This meant that Indonesia and the green open space term have been mentioned 271 times in document collection rather than with the term ecological wisdom. This strengthens previous estimates that most research on green open space was conducted in Indonesia. The number of links to Indonesia also evinces various research topics in Indonesia. This term connected to 37 terms and covered all clusters. It indicated that the green open space research in Indonesia might be discussed in various points of view and it would be useful in policy making process for regional planning in Indonesia.

In contrast, the link strength of Indonesia and ecological wisdom term was found 0 time. It meant that both terms have never been mentioned together and hardly in any research on ecological wisdom. This might be caused by the term ecological wisdom itself that is very rarely used by Indonesian researcher rather than other related term like "local wisdom", "traditional ecological knowledge", or "indigenous knowledge". Ecological wisdom and Ecological knowledge are closely linked in existing literature and relatively similar in the research of traditional ecological knowledge [28]. However, the distinct of both areas lies on their sustainability proven by time. The traditional ecological knowledge should be coming from experiences gained from life and becomes a moral value rather than material thing. It potentially fades with changes in knowledge in technology. While, ecological wisdom is the combination of knowledge and practice coming from good property that evidently sustains with minimal intervention.

On the other hand, the Chinese term linked to green open space and ecological wisdom term had 57 strength and 22 strength respectively. This indicated that the discussion on ecological wisdom was conducted extensively by China as compared with other countries in the document collection. Nevertheless, the China term also occurred together with the green open space term significantly more than the ecological wisdom term. These data indicated that discussion about ecological wisdom is still minimal and could become a potential research topic.

\subsection{Hot Topic Analysis}

The emerging topic can be a hot topic to be discussed through the citation. We attempted to perform hot topic mapping on a collection document to examine this possibility. We calculated the visualization score by average citation and the weight by the occurrences. The overlay colors appeared as a rainbow and the color range was set as $0.5-2.5$ to normalize the score divided by the mean. The "heat" or citation impact ranged from blue (cold) to red (hot) corresponding to the normalized scores from $0.5-2.5$ with a score of 1.5 (green) signifying the average impact. The terms represented by circles were colored to reflect the average citation impact on the term rather than by cluster, as seen in Figure 7 .

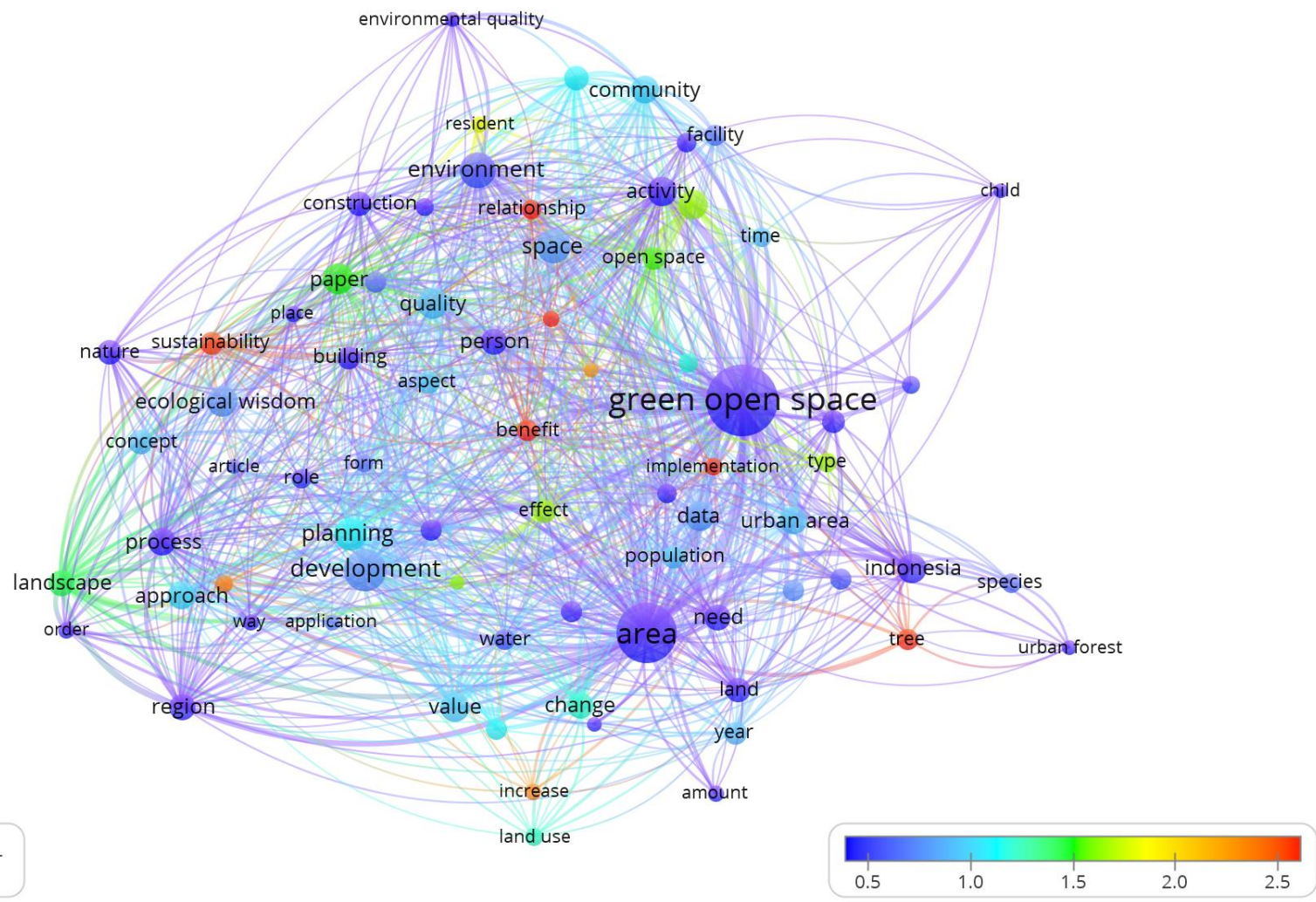

Fig. 7. Hot Topic map of both areas through citation analysis 
Table 3. The hot topic of document collection base on citation impact

\begin{tabular}{lcccc}
\hline \multicolumn{1}{c}{ Term } & Color & Occurrence & size & Cluster \\
\hline Implementation & red & 37 & Small & Urban Green Space \\
Increase & Orange & 32 & Small & Urban Green Space \\
Tree & red & 49 & Small & Urban Green Space \\
Benefit & red & 52 & Small & Environmental quality \\
Resident & Yellow & 34 & Small & Environmental quality \\
Importance & orange & 27 & Small & Sustainable planning \\
Influence & Red & 31 & Small & Sustainable planning \\
Relationship & Red & 47 & Small & Sustainable planning \\
Sustainability & orange & 58 & medium & Sustainable planning \\
information & orange & 35 & small & Landscape Development \\
\hline
\end{tabular}

Ten terms became hot topics (yellow-orange-red color) in document collection and came from all clusters of different compositions (Table 3). The urban green space cluster contributed three terms: "implementation", "increase', and "tree", while the environmental quality cluster contributed two terms: "benefit" and "resident". Further, the sustainable planning cluster became the highest contributors with four terms: "importance', "influence", "relationship", and "sustainability". Finally, the landscape development cluster was the smallest contributor with just one term "information".

\subsection{Potential Research}

The green open space and ecological wisdom approach is often used in urban and environmental development as an effort to achieve a sustainable landscape. However, these two subject areas have been developed independently, as confirmed in previous findings. Therefore, the identification of potential research is needed to enrich studies and build a future direction for research, which would be useful for sustainable landscape development.

We conducted density visualization to identify potential research in both areas in the document collection. Density visualization is a type of VOSviewer's visualization, which indicates the weight of items. It is useful to investigate the topic that appears most and less frequently to discuss document collection by determining the weight of item occurrences and visualizing it by rainbow color. The red areas present the most significant number of items and the highest weights of elements, followed by yellow, green, and blue. The red areas indicate that researchers widely use the words. The words in the yellow area allow researchers to be further investigated, and the words in green and blue areas are the terms that remain to be extensively discussed and have the potential to be explored in future research.

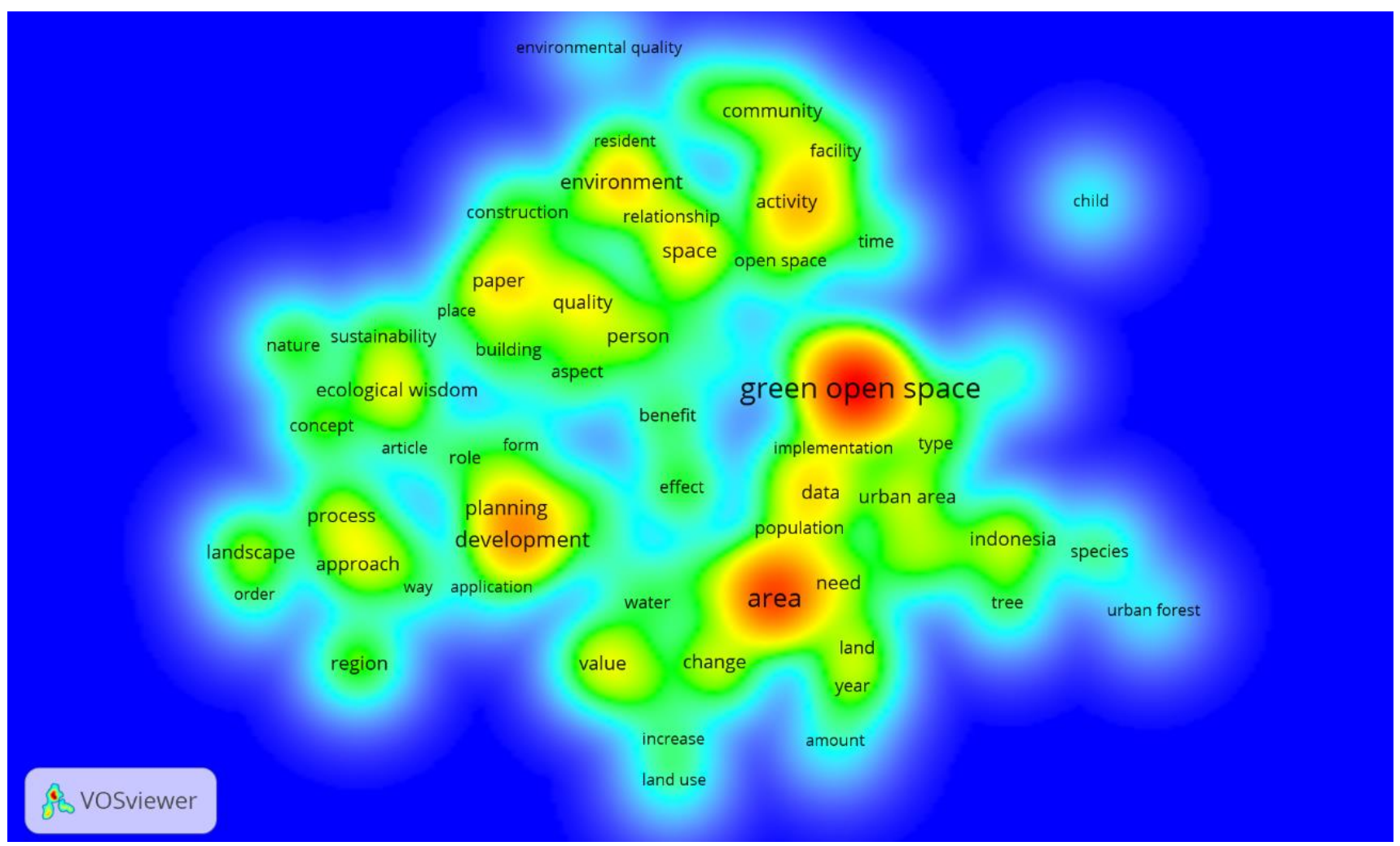

Fig. 8. Terms density visualization of both field 
Figure 8 reveals the terms with the highest density were "green open space" and "area". This indicated that both terms were not specific and widely used in various research topics. Many other words were located in yellow and green. Moreover, the blue area could be assumed to have many potential topics for further investigation related to green open space and ecological wisdom. There are 35 terms located in the yellow area, 15 in the green area, and 18 in the blue area.

According to Table 2 and Figure 8, it was seen that $44 \%$ terms had the potential to be researched in the future. However, we could filter these terms by considering previous findings, especially on publication overview and hot topic analysis to determine the most potential research topic in the field of green open space and ecological wisdom. Finally, we found six terms with high potential for future research due to their high citation impact on science, "increase", "tree", "importance", "benefit", "influence", and "sustainability". Future research on green open space or ecological wisdom should be focused on these terms. Moreover, the findings showed that green open space and ecological wisdom topic did not related each other, and the research, which link both topic in sustainability scope could be considered to fill this lack of study in the future.

\section{Conclusion}

Green open space and ecological wisdom research have become interesting topics discussed in line with the increasing public awareness of the importance of being friendly to the environment. This is evinced by the increase the number of documents related to both topics over the last decade. The trends in both areas were grouped into 4 clusters: urban green space, environmental quality, sustainable planning, and landscape development. Hot topic analysis revealed 10 terms with high citation impact (number of average citations $>7$ citations) and 7 of these came from urban green space and sustainable planning cluster. Overall, there are numerous opportunities to conduct future research in this field, mainly associated with the terms "increase", "tree", "importance", "benefit", "influence", and "sustainability".

\section{References}

1. R. Kaplan, S. Kaplan, The experience of nature: a psychological perspective. Cambridge UK: Cambridge University Press, 1989.

2. T. A. Randall, C. J. Churchill, B. W. Baetz, A GIS-based decision support system for neighbourhood greening, Environ Plan B: Planning and Design 30(4) (2003) 541-563. doi:10.1068/b12970.

3. M. Rakhshandehroo, M. J. M. Yusof, R. Arabi, M. Parva, A Nochian, The Environmental Benefits of Urban Green Open Spaces, Alam Cipta 10(1) (2017) 10-16.

4. R. F. Young, K. Lieberknecht, From smart cities to wise cities: ecological wisdom as a basis for sustainable urban development, Journal of Environmental Planning and Management 62(10)(2019) 1675-1692.

5. W. Shi, H. Woolley, Managing for Multifunctionality in Urban Open Spaces: Approaches for Sustainable Development, J Urban Manag (3) 1-2 (2014) 3-21.
O. C. Dewi, I. Chairunnisa, T. Hidayat, M. Anggraini, A. Napitupulu, Green Open Space: Awareness for Health or Sustainability?, IOP Conference Series: Earth and Environmental Science 120 (2018) 012014.

7. S. Kakoty, Ecology, sustainability and traditional wisdom, J Clean Prod. 172 (2018) 3215-3224.

8. J. Ferris, C. Norman, J. Sempik, People, land and sustainability: Community gardens and the social dimension of sustainable development, Soc Policy Adm. 35 (5) (2001) 559-568.

9. D.T. Patten, The role of ecological wisdom in managing for sustainable interdependent urban and natural ecosystems, Landsc Urban Plan. 155 (2016) 3-10.

10. A. Y. Firmansyah, Architecture Metabolism Approach Which Integrates the Concept Magersari in Supporting Balanced Development with Green Agricultural Land in Suburbs, Procedia - Soc Behav Sci. 227 (2016) 609-616.

11. Y. Kusmarni, M. Holilah, The Ecological Wisdom Values of Agricultural Land Utilization by the Indigenous People of Cigugur Kuningan, West Java, IOP Conference Series: Earth and Environmental Science 145 (2018) 012026

12. S. Barghjelveh, M. Mansouri, S. Y. Islami, The role of ecological networks in "Environmental logic-identity forming" design of urban regions, case study: Isfahan poladshahr urban region, J Environ Stud. 42 (1) (2016) 177194.

13. A. W. Hasyim, R. E. P. Sianturi, A. R. T. Hidayat, Spatial Pattern of Land Cover Change in the Coastal Area of Gresik Regency, Indonesia Using Land Change Modeler, IOP Conference Series: Earth and Environmental Science 328 (2019) 012059.

14. B. Priyono, M. Rahayuningsih, M.S. Arifin, Economic value of trees based on water influence function in Universitas Negeri Semarang (UNNES), Sekaran Campus, Journal of Physics: Conference Series 1321 (2019) 032047.

15. A. Min, J. H. Lee, A conceptual framework for the externalization of ecological Wisdom: The case of traditional Korean gardens, Sustain. 11 (2019) 5298.

16. S. Rennesson, Wrestling beetles and ecological wisdom: How insects contribute to the cosmopolitics of Northern Thailand, Southeast Asian Stud. 8 (1) (2019) 3-24.

17. A. A. K. Darmadi, N. N. Wirasiti, I. K. Ginantra, Diversity of species and benefits of telajakan plant as a potential tourism attraction in Bali, J Environ Manag Tour. 10 (1) (2019) 109118.

18. F. Ali Ikhsan, B. Setioko, A. Suprapti. Ecological wisdom of Hindu- Javanese community settlement in Cetho Hamlet, Lawu Mountains, Central Java, Indonesia, IOP Conference Series: Earth and Environmental Science 99 (2018) 012016.

19. R. Maru, M. R. Abidin, A. Arfan, S. Nyompa, U. Sideng, S. Hasja, Mapping of protected forests and cultivated area in North Luwu South Sulawesi, Indonesia, Asian J Appl Sci. 9 (2016) 189-195.

20. T. Tupan, R. N. Rahayu, R. Rachmawati, E. S. R. Rahayu, Analisis Bibliometrik Perkembangan Penelitian Bidang Ilmu Instrumentasi, Baca J Dokumentasi Dan Inf. 39 (2) (2018) 135-149.

21. H. N. Su, P. C. Lee, Mapping knowledge structure by keyword co-occurrence: A first look at journal papers in Technology Foresight, $\quad$ Scientometrics $85 \quad$ (2010) 65-79. 
C. Chen. Mapping scientific frontiers: The quest for knowledge visualization. London: Springer-Verlag London, 2014.

23. N. J. Van Eck, L. Waltman, Visualizing Bibliometric Networks. Measuring Scholarly Impact, In: Y. Ding, R Rousseau, D. Wolfram, (eds) Measuring Scholarly Impact. Switzerland: CamSpringer, Cham, 2014 https://doi.org/10.1007/978-3-319-10377-8_13.

24. M. E. Falagas, E. I. Pitsouni, G. A. Malietzis, G. Pappas, Comparison of PubMed, Scopus, Web of Science, and Google Scholar: Strengths and weaknesses, FASEB J. 22(2) (2008) $338-42$.
25. N.J. Van Eck, L. Waltman. VOSviewer Manual - version 1.6.8. http://www.vosviewer.com/documentation/Manual_VOSviewe r_1. 5.4.pdf, 2018.

26. P. H. Gobster, (Text) Mining the LANDscape: Themes and trends over 40 years of Landscape and Urban Planning, Landsc Urban Plan. 126 (2014) 21-30.

27. D. Jeong, Y. Koo, Analysis of Trend and Convergence for Science and Technology using the VOSviewer, Int J Contents 12 (3) (2016) 54-58.

28. K. H. Liao, J. K. H. Chan, What is ecological wisdom and how does it relate to ecological knowledge?, Landscape and Urban Planning 155 (2016) 111-113. 